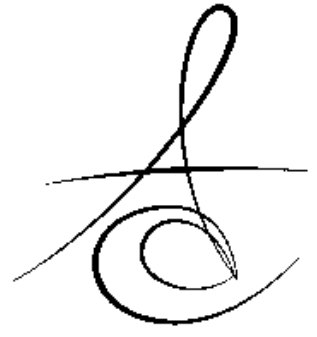

\section{TOTAL DİŞ EKSİKLİĞí OLAN HASTALARIN PANORAMİK MANDİBULAR İNDEKS İLE DEĞERLENDİRİLMESİ}

\author{
EVALUATION OF EDENTULOUS PATIENTS WITH PANORAMIC \\ MANDIBULAR INDEX
}

\author{
Doç.Dr. Semanur DöLEKOĞLU* \\ Doç.Dr. Zeynep ÖZKURT***
}

Yrd.Doç.Dr. Hare GÜRSOY
Doç.Dr. Ceyda ÖZÇAKIR TOMRUK

Makale Kodu/Article code: 2062

Makale Gönderilme tarihi: 09.01.2015

Kabul Tarihi: 09.04.2015

\section{ÖZET}

Amaç: Bu çalışmanın amacı total diş eksikliği olan, iskelet metabolizmasını etkileyebilecek sistemik hastalığı olan ve olmayan hastaları, panoramik mandibular indeks (PMI) kullanarak alt çene kemik kaliteleri açısından değerlendirmektir.

Materyal ve Metod:Total diş eksikliği olan ve panoramik radyografi çekilmiş 47 hasta retrospektif olarak değerlendirildi. Hastaların tıbbi anamnezleri incelendi ve iskelet metabolizmasını etkileyebilecek bir hastalığı olan 17 hasta ile, iskelet metabolizmasını etkileyebilecek hastalığı olmayan 30 hasta çalışmaya dahil edildi. Panoramik radyografiler üzerinde alt çene sağ ve sol foramen mentale bölgelerinde ölçümler yapılarak inferior ve superior PMİ değerleri hesaplandıktan sonra istatistiksel analizler yapıldı.

Bulgular: Sağ ve sol inferior PMİ ortalaması $0.34 \pm 0.08$, sağ ve sol superior PMİ ortalaması $0.28 \pm 0.07$ olarak bulundu. Cinsiyet, yaş ve sistemik hastalığa göre inferior ve superior PMİ değerlerine bakıldığında istatistiksel olarak anlamlı bir farklılık bulunmadı ( $p>0.05$ ).

Sonuç:Diş hekimliğinde özellikle osteoporotik hastaların veya düşük kemik mineral yoğunluğu olan kişilerin belirlenmesinde, değerlendirilmesinde ve protetik planlamasında panoramik radyografilerin önemli bir rolü olduğu düşünülmektedir

Anahtar kelimeler: Total diş eksikliği, panoramik mandibular indeks.

\section{ABSTRACT}

Aim: Son yıkamada kullanılan farklı kök kanal Aim: Evaluation of mandibular bone quality of healthy edentulous patients and edentulous patients with some disorders affecting skeletal metabolism with comparison according to panoramic mandibular index (PMI) values.

Material and Method: 47 edentulous patients with panoramic radiographs were included in this study. Medical histories of these patients were reviewed. 17 patients with systemic disorders affecting skeletal metabolism were regarded as study group while control group consisted of 30 patients that have no systemic diseases which might affect skeletal metabolism. Measurements were performed in the right and left mental foramen regions on panoramic radiographs and statistical analysis was made after determination of inferior and superior PMI values.

Results: Right and left inferior PMI and right and left superior PMI means were found as $0.34 \pm 0.08$ and $0.28 \pm 0.07$, respectively. Inferior and superior PMI values were not statistically significant when age, sex and systemic disorders has taken into consider ( $p>0.05)$.

Conclusion: Comparison of healthy edentulous patients and edentulous patients with some disorders affecting skeletal metabolism showed no statistically significant differences according to panoramic mandibular index.

Key words: Edentulism, panoramic mandibular index.

\footnotetext{
* Yeditepe Üniversitesi Dişhekimliği Fakültesi Ağız Diş Çene Radyolojsii Anabilim Dalı

** Yeditepe Üniversitesi Dişhekimliği Fakültesi Periodontoloji Anabilim Dalı

***Yeditepe Üniversitesi Dişhekimliği Fakültesi Protetik Diş Tedavisi Anabilim Dalı

**** Yeditepe Üniversitesi Dişhekimliği Fakültesi Ağız, Diş, Çene Hastalıkları ve Cerrahisi Anabilim Dalı
} 


\section{GİRIŞ}

Kemik kalitesi; kemiğin kortikal kalınlığı, trabeküler kalınlığı, dansite ve özellikle kemik mineral yoğunluğunu tanımlar. ${ }^{1,2}$ Kemiğin kalite ve kantitesindeki değişiklikler, kemik hastalıkları, protetik uygulamalar ve özellikle implantolojide çok önemlidir. Diş çekiminden sonra mandibula ve maksillada kret rezorpsiyonu oluşur. ${ }^{3,4}$ Rezopsiyonun boyutunu; kemik hacmi, kas fonksiyonu, beslenme, çekim hikâyesi, hayatın erken ve menopoz dönemindeki hormonal faktörler belirler. Kemik dansitesindeki azalma ve porozitedeki artma hayatın yaklaşık 3. dekatında başlar. ${ }^{5}$ Kemik kalitesi; düşük kemik kütlesinin ve fraktür riskinin belirlenmesinde, ağrı ve sakatlıkların önlenmesinde ve implantojide büyük öneme sahiptir. ${ }^{1,2,6-8}$

Osteoporoz riski bulunan hastaların veya düşük kemik mineral yoğunluğu olan kişilerin erken dönemde belirlenmesi tedavinin seyri açısından önemlidir. Osteoporoz kemik yoğunluğunda azalma ve mikro yapısındaki bozulmalarla karakterize, kırılganlık artışı ve kırık riskine yol açan sistemik bir hastalıktır. ${ }^{9,10}$ Osteoporozlu hastaların yanı sıra osteopenili hastalarda da ciddi anlamda kırık riski vardır. Osteoporotik kırıkların önemli bir kısmının osteopenik grupta görüldüğü bildirilmektedir. ${ }^{11,12}$ İskeletsel osteopeni tanısı genellikle kalça ya da lumbar omurga radyografilerinden konulur ve kemik densitometri endikasyonu gelişir. ${ }^{13-15}$ Osteoporozda teşhis yöntemlerinin pahalı olması, diş hekimlerini dental radyografilerle osteoporozun tanısına yöneltmiştir. Osteoporozun teşhis edilmesinde dental radyografilerin tanı değeriyle ilgili birçok çalışma yapılmıştır. 6,16,17

Panoramik radyografiler, alt-üst çene dişleri, temporomandibular eklemleri, çene kemikleri ve çevre dokularını görmek için kullanılmaktadır. ${ }^{18}$ Son yıllarda yapılan klinik çalışmalarda osteoporotik hastaların veya düşük kemik mineral yoğunluğu olan kişilerin belirlenmesinde ve değerlendirilmesinde panoramik radyografilerin önemli bir rolü olduğu belirtilmektedir. ${ }^{10,19-21}$ Alt çenenin kemik kalitesini belirlemek amacıyla panoramik radyografiler üzerinde ölçümler yapılarak uygulanan değişik mandibular radyomorfometrik indeksler geliştirilmiştir. Mandibula korteksinin poroziter görünüşünün sınıflandırıldığı mandibular kortikal indeks ${ }^{22}$ (MKİ), mental foramen bölgesinde mandibula kortikal genişliğinin ölçüldüğü mental index ${ }^{5}$ (MI), ve mandibula korteks kalınlığının mental foramenin alt sınırından mandibula kortikal kemiğin alt sınırına olan mesafenin oranının hesaplandığı panoramik mandibular indeks ${ }^{23}$ (PMİ) bu indekslerden bazılarıdır.

$\mathrm{Bu}$ çalışmanın amacı total diş eksikliği olan, iskelet metabolizmasını etkileyebilecek hastalığı bulunan ve bulunmayan hastaların alt çene kemik kalınlıklarını, panoramik mandibular indeks değerlerini hesaplayarak incelemektir

\section{MATERYAL VE METOD}

2009 ve 2010 yılları arasında Yeditepe Üniversitesi, Diş Hekimliği Fakültesi, Oral Diagnoz ve Radyoloji kliniğine başvuran, total diş eksikliği olan ve panoramik radyografi istemi yapılmış hastalar retrospektif olarak incelendiğinde 69 kişi olduğu saptandı. 69 hastanın 53'ünden panoramik radyografi çekildiği belirlendi. Panoramik radyografiler tanısal olarak kabul edilebilirlikleri (hasta konumlandırması, baş pozisyonlandırılması düzgün, film densite ve kontrastı iyi) açısından değerlendirildi. Foramen mentalenin tam olarak belirlenemediği radyografiler çalışma dışı bırakıldı. Toplam 47 hasta çalışma grubu olarak değerlendirildi ve bu hastaların tıbbi anamnezleri incelendi. Çalışma grubu, iskelet metabolizmasını etkileyebilecek hastalığı olan 17 hasta ve iskelet metabolizmasını etkileyebilecek hastalığı olmayan 30 hastadan oluşturuldu.

Aynı dijital panoramik radyografi cihazı (Planmeca Promax, Helsinki, Finland) kullanılarak elde edilmiş olan dijital panoramik radyografilerdeki lineer ölçümler, Planmeca cihazına ait bir software programı olan Dimaxis kullanılarak yapıldı. Ölçümler oral diagnoz ve radyoloji uzmanı tarafından yapıldı. Görüntüler büyütme oranını ortadan kaldırmak amacıyla öncelikle ka libre edildi. Sağ ve sol inferior ve superior PMI'ye ilişkin 47 ölçümün 15'i gözlemci tarafından rastgele seçilerek tekrar ölçüldü. Panoramik mandibular indeks ölçümleri iki şekilde yapıldı: hem sağ foramen mentalenin üst kenarından ve alt kenarından hem de sol foramen mentalenin üst kenarından ve alt kenarından olacak şekilde Benson'un ${ }^{23}$ tanımına göre yapıldı.

Çalışmada elde edilen bulgular değerlendirilirken, istatistiksel analizler için SPSS (Statistical Package for Social Sciences) for Windows 15.0 programı kullanıldı. Çalışma verileri değerlendirilirken tanımlayıcı istatistiksel metodların (Ortalama, Standart sapma) yanısıra niceliksel verilerin karşılaştırılmasında parametreler normal dağılıma uygunluk gösterdiğinden

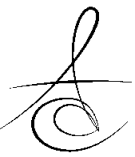


parametrelerin ikiden fazla gruplar arası karşılaştırmalarında Oneway Anova testi; iki grup arası değerlendirmelerinde ise Student $\mathrm{t}$ test kullanıldı. Parametrelerin grup içi karşılaştırmalarında paired sample $t$ testi kullanıldı. Niteliksel verilerin karşılaştırımasında ise KiKare testi kullanıldı. Parametre ölçümlerine ilişkin meod hatasının analizinde Sınıf içi korelasyon katsayısı (ICC) hesaplanmıştır. Anlamlılık $\mathrm{p}<0.05$ düzeyinde değerlendirildi.

\section{BULGULAR}

Çalışmaya dahil edilen toplam 47 hastanın yaşları 52 ile 93 arasında değişmekte olup, ortalama

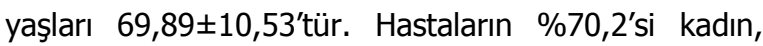
$\% 29,8^{\prime}$ i erkek olup \%36,2'sinin iskelet metabolizmasını etkileyebilecek hastalığı bulunmaktadır. Hastalara ait demografik bilgilerin dağılımı Tablo 1'de görülmektedir.

Tablo 1. Demografik bilgilerin dağılımı.

\begin{tabular}{llll}
\hline & & n & \% \\
\hline \hline \multirow{2}{*}{ Cinsiyet } & Kadın & 33 & 70,2 \\
& Erkek & 14 & 29,8 \\
\hline \multirow{3}{*}{ Yaş } & $\mathbf{5 0 - 5 9}$ & 9 & 19,1 \\
& $\mathbf{6 0 - 6 9}$ & 16 & 34,0 \\
& $\mathbf{7 0 - 7 9}$ & 13 & 27,7 \\
& $\mathbf{2 8 0}$ & 9 & 19,1 \\
\hline \multirow{2}{*}{ Iskelet } & Var & 17 & 36,2 \\
metabolizmasını & Tiroid & 2 & 4,3 \\
etkileyebilecek & Osteoporoz & 5 & 10,6 \\
hastalık & Kanser+Bifosfonat & 7 & 14,9 \\
& nekrozu & 2 & 4,3 \\
& Yok & 30 & 2,1 \\
\hline
\end{tabular}

Tablo 2'de cinsiyet ve yaşa göre sistemik hastalıkların değerlendirilmesi belirtilmiştir. Cinsiyetlere göre olgularda iskelet metabolizmasını etkileyebilecek sistemik hastalık görülme oranları arasında istatistiksel olarak anlamlı bir farklılık bulunmamaktadır ( $p>0.05$ ). Kadınların \%39,4'ünde, erkeklerin de \%28,6'sında sistemik hastalık görülmektedir.

Yaş gruplarına göre iskelet metabolizmasını etkileyebilecek bir sistemik hastalık görülme oranları arasında istatistiksel olarak anlamlı bir farklılık bulunmamaktadır ( $p>0.05$ ). 50-59 yaş arası olguların \%33,3'ünde, 60-69 yaş arası olguların \%31,3'ünde, 70-79 yaş arası olguların $\% 38,5^{\prime}$ inde ve 80 yaş ve üzerinde olan olguların da \%44,4'ünde iskelet metabolizmasını etkileyebilecek bir sistemik hastalık görülmektedir.

Tablo 2. Cinsiyet ve yaşa göre sistemik hastalıkların değerlendirilmesi.

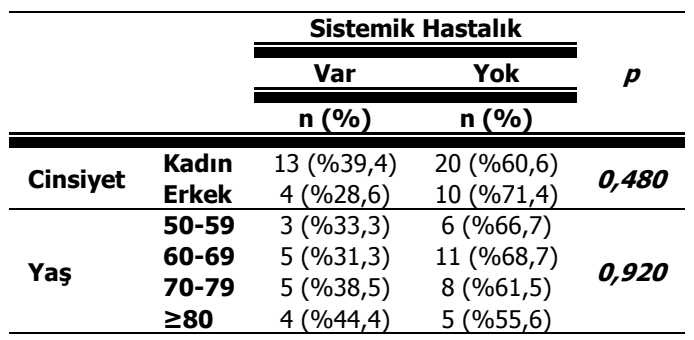

Tablo 3'deki sağ ve sol inferior PMİ ve superior PMİ değerlendirilmelerine bakıldığında, sağ ve sol inferior PMİ ortalamaları arasında istatistiksel olarak anlamlı bir farklılık bulunmamaktadır ( $p>0.05)$. İstatistiksel olarak anlamlı bir farklılık bulunmadığı için sağ ve sol inferior PMI için hesaplanan ortalama

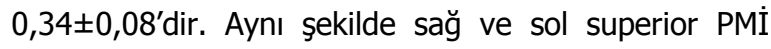
ortalamaları arasında da istatistiksel olarak anlamlı bir farklılık bulunmadığı için $(p>0.05)$ superior PMI ortalaması $0,28 \pm 0,07$ olarak hesaplanmış ve sonraki analizlerde ortalama değerler kullanılmıştır.

Tablo 3. Sağ ve sol İnferior PMİ ve superior PMI değerlendirilmesi.

\begin{tabular}{lccc}
\hline & Sağ & Sol & \multirow{2}{*}{$\boldsymbol{p}$} \\
\cline { 2 - 3 } & Ort \pm SS & Ort \pm SS & \\
\hline \hline İnferior PMİ & $0,34 \pm 0,09$ & $0,33 \pm 0,08$ & $\mathbf{0 , 2 5 0}$ \\
\hline Superior PMİ & $0,29 \pm 0,07$ & $0,28 \pm 0,06$ & $\mathbf{0 , 2 8 8}$ \\
\hline
\end{tabular}

Cinsiyet, yaş ve iskelet metabolizmasını etkileyebilecek sistemik hastalığa göre inferior PMI değerlendirilmesine bakıldığında istatistiksel olarak anlamlı bir farklılık bulunmadığı Tablo 4'de görülmektedir ( $p>0,05)$. Tablo $5^{\prime}$ e bakıldığında yine aynı şekilde, cinsiyet, yaş ve iskelet metabolizmasını etkileyebilecek sistemik hastalığa göre yapılan superior PMİ karşılaştırmalarında aralarında istatistiksel olarak anlamlı bir farklılık bulunmamaktadır ( $p>0,05)$.

Sağ ve sol inferior ve superior PMI'ye ilişkin 47 ölçümün 15'i gözlemci tarafından rastgele seçilerek tekrar ölçüldüğünde, tüm ölçümlerde belirlenen sınıf içi korelasyon katsayıları 0,993 ile 0,998 arasında elde edilmiştir (Tablo 6) .

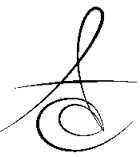


Tablo 4. Cinsiyet, yaş ve iskelet metabolizmasını etkileyebilecek hastalığa göre inferior PMİ değerlendirilmesi.

\begin{tabular}{|c|c|c|c|}
\hline & & $\begin{array}{c}\text { İnferior } \\
\text { PMİ }\end{array}$ & $p$ \\
\hline & & Ort $\pm S S$ & \\
\hline${ }^{+}$Cinsiyet & $\begin{array}{l}\text { Kadın } \\
\text { Erkek }\end{array}$ & $\begin{array}{l}0,33 \pm 0,08 \\
0,36 \pm 0,06\end{array}$ & 0,199 \\
\hline & 50-59 & $0,36 \pm 0,05$ & \\
\hline 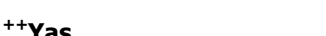 & 60-69 & $0,36 \pm 0,06$ & 0,123 \\
\hline ras & 70-79 & $0,32 \pm 0,07$ & 0,123 \\
\hline & $\geq 80$ & $0,30 \pm 0,12$ & \\
\hline & Var & $0,34 \pm 0,06$ & \\
\hline & & & \\
\hline & Yok & $0,33 \pm 0,09$ & \\
\hline
\end{tabular}

Tablo 5. Cinsiyet, yas ve iskelet metabolizmasını etkileyebilecek hastalığa göre superior PMİ değerlendirilmesi.

\begin{tabular}{|c|c|c|c|}
\hline & & Superior PMI & $p$ \\
\hline${ }^{+}$Cinsiyet & $\begin{array}{l}\text { Kadın } \\
\text { Erkek }\end{array}$ & $\begin{array}{l}0,27 \pm 0,07 \\
0,30 \pm 0,05\end{array}$ & 0,158 \\
\hline${ }^{++}$Yaş & $\begin{array}{l}50-59 \\
60-69 \\
70-79 \\
\geq 80 \\
\end{array}$ & $\begin{array}{l}0,31 \pm 0,03 \\
0,30 \pm 0,05 \\
0,26 \pm 0,06 \\
0,25 \pm 0,10\end{array}$ & 0,115 \\
\hline $\begin{array}{l}\text { + İskelet metabolizmasını } \\
\text { etkileyebilecek hastalık }\end{array}$ & $\begin{array}{l}\text { Var } \\
\text { Yok }\end{array}$ & $\begin{array}{l}0,29 \pm 0,05 \\
0,28 \pm 0,07\end{array}$ & 0,729 \\
\hline
\end{tabular}

Tablo 6. Sağ ve sol inferior PMI ve superior PMI'ye ilişkin sınıf içi korelasyon katsayısı.

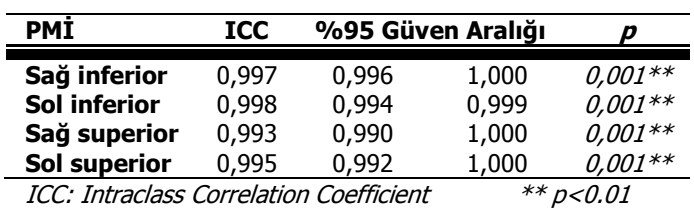

\section{TARTIŞMA}

Ağızda mevcut olan dişleri destekleyen yapı olan alveol kreti dişler çekildikten sonra rezorbe olmaya başlar ve bu fizyolojik bir proçestir. Diş çekiminden sonraki ilk yılda, alveol kretinde vertikal yönde kemik seviyesinde önemli bir azalma olur ve daha sonraki yllarda kemik rezorpsiyonu azalarak devam eder. Kalan alveoler yapıya "rezidüel alveoler kret" adı verilir. Rezidüel alveoler kret rezorpsiyonu, her iki çenede de görülmekle birlikte, mandibulada daha şiddetli olmaktadır. ${ }^{24}$ Etyolojisi komplekstir ve pek çok faktöre bağılır. Bunlar arasında yaş, cinsiyet, fasiye ölçme, morfoloji dişsizlik süresi, protezi kullanma alışkanlıkları, beslenme, genel sağlık, sistemik hastalıklar ve osteoporoz sayılabilir. 5,24,25

Rezidüel alveoler kret, protezin stabilizasyonu ve fonksiyonel biçimde kullanılabilmesi veya implant uygulamaları yapılacaksa planlama açısından önemlidir. Doğal dişlerin kaybedilmesinden sonra alveol kretlerin büyüklüğü ve şekli değişir. Çünkü diş kaybiyla birlikte kemikte bir rezorpsiyon baslar. Başlangıçta hızı olan rezorpsiyon gittikçe yavaşlayarak hayat boyu devam eder. ${ }^{24}$

Kemik yapısının kalitatif ve kantitatif incelenmesi, farklı yöntemlerle yapılır. Diş hekimliğinde kemik yapısıyla ilgili çalışmaların çoğu, ideal implant planlaması için yapılmıştır. Bu çalışmalarda, uygulanacak implantların sayısı, çapı, yeri, açısı ve anatomik oluşumlara olan uzaklığı ile mevcut kemiğin miktarı, yoğunluğu araştırılmıştır. ${ }^{17,26,27}$

Çene kemiklerinin kalite ve kantitesini belirlemek amacıyla geliştirilen radyomorfometrik yöntemlerde radyografilerde trabeküler kemikten daha kolay izlenen kortikal kemik ölçümleri esas alınmıştır. Temel çiğneme kaslarının tutunma yerleriyle bağlantıı olmayan mental foramen bölgesi standart inceleme alanı olarak kullanılmıştır. ${ }^{28-30}$ Mental foramenin distalindeki bölgelerde bukkal korteksle iskeletin mineral yoğunluk değerleri arasındaki ilişki linguale göre daha iyidir. Bu nedenle panoramik radyografi görüntülerinde kolay görülebilen ve özellikle bukkal kısmı iskeletin mineral durumunu yansıtan inferior korteks en iyi çalışma bölgesi olarak tanımlanmışır. ${ }^{23,28,31}$ Biz de çalışmamızda mental foramen bölgesinde hem kortikal kemik kalınıı̆ını ölçmeyi, hem de mental foramenin alt ve üst sınılarından kortikal kemiğin alt sınırına olan mesafeleri ölçmeyi gerektiren panoramik mandibular indeksi kullandık.

80 yaş ve üstü grubunda sistemik hastalık daha fazla görülmekle beraber, istatistiksel olarak yaş gruplarına göre sistemik hastalık görülme oranlarında anlamlı bir farklıık bulunmamaktadır.

Ledgerton ve ark. ${ }^{13} 25-74$ yaş arası kadınlarda yaptıkları çalışmada tüm popülasyon için ortalama inferior PMİ değerini 0.31 ve ortalama superior PMİ değerini ise 0,26 bulmuşlardır.

Yüzügüllü ve ark. ${ }^{32}$ total diş eksikliği olan hastalarda yaptıkları çalışmada PMİ değerlerinin cinsiyet ve yaştan etkilenmediğini bulmuşlardır. Bir diğer çalışmada da cinsiyetlere göre PMİ ve Mİ değerlerinde fark olmadığı belirtilmiştir. ${ }^{33}$ Bu çalışmada da, diğer çalışmalarla uyumlu olarak yaş gruplarına göre inferior

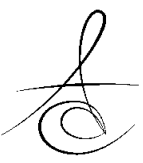


ve superior PMİ değerlerinin yaş arttıkça azaldığı fakat bunun istatistiksel olarak anlamlı olmadığı ve cinsiyetle de ilişkisi olmadığı saptanmıştır. Bununla beraber PMI'i bulan araştırmacı olan Benson ${ }^{23}, 1991$ yllında yaptığı çalışmasında, yetmişli yaşlarındaki kadınların PMI değerlerinin otuzlu ve kırklı yaşlardakilere göre oldukça düşük olduğunu belirtmiştir. Bizim çalışmamızda sadece total diş eksikliği olan hasta grubunu aldığımız ve yaş aralığı 52 'den başladığı için iki çalışmayı karşılaştırmak uygun değildir.

Bu çalışmada kemiği etkileyebilecek bir sistemik hastalığı olan ve ilaç kullanan hastalarla, kemik metabolizmasını etkileyebilecek bir hastalığı olmayan hastaların inferior ve superior PMI değerleri arasında istatistiksel olarak anlamlı bir farklılık bulunmamıştır. Total diş eksikliği olan, kemik metabolizmasını etkileyen hastalığı olanlar ve olmayanlar olarak ayırdığımız iki grup arasında PMI değerleri açısından istatistiksel olarak anlamlı bir fark olmamasının nedenleri arasında, hastaların hastalık sürelerinin ve diş kayıplarının ne zaman olduğunun önemli olabileceğini düşünmekteyiz.

Gülşahi ve ark ${ }^{33}$. (2010) total dişsiz hastalarda çenelerin kemik mineral yoğunluğunu ve radyomorfometrik indekslerle ilişkisini değerlendirdikleri çalışmalarında normal, osteoporozlu/osteopenili ve tüm hastalar için inferior PMI değerleri sırasıyla 0,33, 0,26 ve 0,30 olduğunu belirtmişlerdir.

Bizim çalışmamızda tüm hastalar için inferior PMI ortalaması $0,34 \pm 0,08$, superior PMI ortalaması ise $0,28 \pm 0,07$ olup diğer çalışmalarla benzerlik göstermektedir.

PMI'in MI ve mandibular kortikal genişliğe (MCW) göre bir avantajı, hesaplamalarda değişik panoramik radyografi cihazlarından kaynaklanan farklı büyütme oranlarını dikkate almasıdır. Bu sayede, diğer lineer indislere göre farklı çalışmalarla karşılaştırlabilmesi mümkündür. ${ }^{13}$

Sağ ve sol inferior ve superior PMI'ye ilişkin 47 ölçümün 15'i gözlemci tarafından rastgele seçilerek tekrar ölçüldüğünde, tüm ölçümlerde belirlenen sınıf içi korelasyon katsayıları 0.993 ile 0.998 arasında elde edilmiştir. Bu da ölçümler arasındaki uyumun çok iyi düzeyde olduğunu ve PMI ölçümlerinin sonuçları etkilemeyecek ve önemli olmayan bir hata ile tekrarlanabileceğini göstermektedir.

Total diş eksikliği olan, iskelet metabolizmasını etkileyen bir rahatsızlğı bulunan hastaları, iskelet metabolizmasını etkileyen bir rahatsızığı olmayan hastalarla panoramik mandibular indeks değerleri açısından karşılaşırmayı amaçladığımız çalışmada iki grup arasında istatistiksel olarak anlamlı bir fark saptanmamıştır.

Dişhekimliğinde panoramik radyografinin kullanımı oldukça yaygındır. Son yıllarda yapılan çalışmalarda panoramik radyografinin osteoporotik kırık için yüksek risk taşıyanların saptanmasında kullanılan araçlardan biri olabileceği belirtilmektedir. ${ }^{34-37}$ Panoramik radyografide kemik mineral yoğunluğunda azalma olduğu görülen hastaların osteoporoz açısından ilgili doktorlara yönlendirilmesinde, bu kişilerde oluşabilecek kırıkların ve hayati tehlikenin önlenmesinde ve bu hastalara yapilacak konvansiyonel ve/veya implantüstü protez planlamasında diş hekimine büyük görev düşmektedir.

\section{KAYNAKLAR}

1. Friberg B, Ekestubbe A, Mellström $D$, et al. Branemark implants and osteoporosis: A clinical exploratory study. Clinical İmpl Dent and Rel Res. 2001;3:50-6.

2. Bianchi A, Sanfilippo F. Osteoporosis: The effect on mandibular bone resorption and therapeutic possibilities by means of implant protheses. Int J Periodontics Restorative Dent. 2002;22:231-9.

3. Atwood DA. Some clinical factors related to rate of resorption of residual ridges. J Prosthet Dent. 1962;12:441-50.

4. Tallgren A. A continuing reduction of the residualalveolar ridges in complete denture wearers. A mixed-longitudinal study covering 25 years . J Prost Dent. 1972;26:120-32.

5. Çakur B. Mandibular kemiğin kantitatif değerlendirilmesinde panoramik radyogramın dansitometre değerleri ile dual energy $\mathrm{x}$-ray absobsiyometri değerlerinin karşılaştııılması. Doktora tezi, Erzurum, 2005.

6. Akdeniz BG. Endosseöz implantlarda seçilen bölgenin elverişliliğinin panoramik radyografi ve bilgisayarlı tomografi kullanımı ile kalitatif ve kantitatif olarak kıyaslamalı değerlendirilmesi. Ege Üniversitesi Sağlık Bilimleri Enstitüsü Oral Diagnoz ve Radyoloji Anabilim Dalı, Doktora tezi İzmir, 1995. 
7. Bidez MW, Misch CE. Issues in bones mechanics related to oral implants. Implant Dentistry. 1992; 1:289-94.

8. Misch CE. Density of bone. Int. J. Oral Implantol. 1990;6:23-31.

9. Lee $\mathrm{BD}$, White $\mathrm{SC}$. Age and trabecular features of alveolar bone associated with osteoporosis. Oral Surg Oral Med Oral Pathol Oral Radiol Endod. 2005; 100:92-8.

10. Dagistan S, Bilge OM. Comparison of antegonial index, mental index, panoramic mandibular index and mandibular cortical index values in the panoramic radiographs of normal males and male patients with osteoporosis. Dentomaxillofac Radiol. 2010;39:290-4.

11. Atik OS. Osteoporotik kırık riski hesaplaması. Eklem Hastalık Cerrahisi. 2008;19:1.

12. Siris ES, Chen YT, Abbott TA, et al. Bone mineral density thresholds for pharmacological intervention to prevent fractures. Arch Intern Med. 2004;164:1108-12.

13. Ledgerton D, Horner $K$, Devlin $H$, et al. Radiomorphometric indices of the mandible in a British female population. Dentomaxillofac Radiol. 1999;28:173-81.

14. Masud T, Jawed S, Doyle DV, et al. A population study of the screening potential of assessment of trabecular pattern of the femoral neck (Singh index): the Chingford Study. $\mathrm{Br} \mathrm{J}$ Radiol. 1995;68:389-93.

15. Masud T, Mootoosamy I, McCloskey EV, O'Sullivan MP, Whitby EP, King D, Matson MB, Doyle DV, Spector TD. Assessment of osteopenia from spine radiographs using two different methods: the Chingford Study. $\mathrm{Br}$ J Radiol. 1996;69:451-6.

16. Horner K, Devlin $\mathrm{H}$. The relationships between two indices of mandibular bone quality and bone mineral density measured by dual energy $X$ - ray absortiometry. Dentomaxillofacial Radiology. 1998;27:17-21.

17. Horner $\mathrm{K}$, Devlin $\mathrm{H}$. The relationship between mandibular bone mineral density and panoramic radiographic measurements. J Dent. 1998;26: 337-43.
18. Peker İ, Toraman Alkurt M., Yıldırım Biçer AZ.Total Ve Parsiyel Dişsiz Çenelerin Panoramik Radyografi Kullanılarak Değerlendirilmesi. Atatürk Üniv. Diş Hek. Fak. Derg. J Dent Fac Atatürk Uni 2014;24 241-5

19. Thanyakarn C, Hansen K, Rohlin $M$, et al. Measurements of tooth length in panoramic radiographs. 1. The use of indicators. Dentomaxillofac Radiol. 1992;21:26-30.

20. Bollen AM, Taguchi A, Hujoel PP, et al. Casecontrol study on self-reported osteoporotic fractures and mandibular cortical bone. Oral Surg Oral Med Oral Pathol Oral Radiol Endod. 2000;90:518-24.

21. Drozdzowska B, Pluskiewicz W, Tarnawska B. Panoramic-based mandibular indices in relation to mandibular bone mineral density and skeletal status assessed by dual energy X-ray absorptiometry and quantitative ultrasound. Dentomaxillofac Radiol. 2002;31:361-7.

22. Klemetti $E$, Kolmakov $S$, Kröger $H$. Pantomography in assessment of the osteoporosis risk group. Scand J Dent Res. 1994;102:68-72.

23. Benson BW, Prihoda TJ, Glass BJ. Variations in adult cortical bone mass as measured by a panoramic mandibular index. Oral Surg Oral Med Oral Pathol. 1991;71:349-56.

24. Çalıkkocaoglu S. Tam Protezler. Cilt 1. 3.baskı. Protez Akademisi ve Gnatoloji Derneği yayını. İstanbul, 1998;30- 31, 40- 47, 48- 51.

25. Canger E.M, Çelenk P. Radiographic evaluation of alveolar ridge heights of dentateand edentulous patients. Gerodontology. 2010 Jun 2. [Epub ahead of print]

26. Lindh C, Petersson A, Rohlin M. Assessment of the trabecular pattern before endosseous implant treatment: diagnostic outcome of periapical radiography inthe mandible. Oral Surg Oral Med Oral Pathol Oral Radiol Oral Endod1996;82:33543.

27. Daiodone R. Use of computed tomography for selection of implant sites.Dentomaxillofac Radiol (Abstr) 1994;23:58.

28. Önem $E$, Güneri $P$, Bir $Y$. Diş hekimliğinde kemik kalitesinin belirlenmesi: Radyografik yöntemler ve yorumları. Ondokuz Mayıs Üniv Diş Hekim Fak Derg. 2007;8:190-9. 
29. Mohajery M, Brooks SL. Oral radiographs in the detection of early signs of osteoporosis. Oral Surg Oral Med Oral Pathol. 1992;73:112-7.

30. Kribbs PJ, Smith DE, Chesnut $\mathrm{CH}$ 3rd. Oral findings in osteoporosis. Part I: Measurement of mandibular bone density. J Prosthet Dent. 1983;50:576-9.

31. Taguchi A, Sanada M, Krall E, et al. Relationship between dental panoramic radiographic findings and biochemical markers of bone turnover. J Bone Miner Res. 2003;18:1689-94.

32. Gulsahi A, Paksoy CS, Ozden S, et al. Assessment of bone mineral density in the jaws and its relationship to radiomorphometric indices. Dentomaxillofac Radiol. 2010;39:284-9.

33. Yüzügüllü $B$, Gulsahi $A$, Imirzalioglu $P$. Radiomorphometric indices and their relation to alveolar bone loss in completely edentulous Turkish patients: A retrospective study. J Prosthet Dent. 2009;101:160-5.

34. Gulsahi $A$, Yüzügüllü $B$, Imirzalioglu $P$, ve ark. Assessment of panoramic radiomorphometric indices in Turkish patients of different age groups, gender and dental status. Dentomaxillofac Radiol. 2008;37:288-92.

35. Güngör K, Akarslan Z, Akdevelioglu $M$, ve ark. The precision of the panoramic mandibular index. Dentomaxillofac Radiol. 2006;35:442-6.

36. Taguchi A, Tsuda M, Ohtsuka $M$, et al. Use of dental panoramic radiographs in identifying younger postmenopausal women with osteoporosis. Osteoporos Int. 2006;17:387-94.

37. Zlatarić DK, Celebić A. Clinical bone densitometric evaluation of the mandible in removable denture wearers dependent on the morphology of the mandibular cortex. J Prosthet Dent. 2003;90:8691

\section{Yazışma Adresi:}

Ceyda Özçakır Tomruk

Yeditepe Üniversitesi Diş Hekimliği Fakültesi

Bağdat Caddesi No:238

Göztepe/İstanbul

Tel: 02163636044

GSM: 05324616222

Fax: 02163636211

E-mail: ceydaozcakir@yahoo.com 